\title{
Recycling of rubber waste in sand concrete
}

\author{
Guendouz M 1,*, Boukhelkhal Dj ${ }^{2}$
}

1,* LME Laboratory, University of Medea, Medea, Algeria.

2 Geomaterials Laboratory, University of Blida, Blida, Algeria.

* Corresponding Author: guen12moh@gmail.com

\begin{abstract}
The large development in the consumption of rubber is observed in the recent years, which leads to an increase of the production of rubber related waste. Rubbers are not hazardous waste, but they constitute a hazard for both environment and health, in case of fire in storage sites. So, recycling appears as one of the best solutions for disposing of rubber waste.This paper presents an experimental investigation dealing with the valorisation of rubber waste, specifically rubber obtained from old shoes sole waste. The waste rubbers are used form $(0 / 5 \mathrm{~mm})$ to mixes as addition at percentage $(10 \%, 20 \%, 30 \%$ and $40 \%)$ in sand concrete. The physical (workability, bulk density), mechanical (compressive and flexural strength) and thermal properties are studied and analysed.The results indicate that the incorporation of rubber waste particles in sand concrete contributes to increase the workability and reduce the bulk density of all studied sand concrete. The obtained results show that mechanical performance (compressive and flexural strength) decreases when the rubber content increases. Nevertheless, the presence of rubber aggregate leads to a significant reduction in thermal conductivity, which improves the thermal insulation performances of sand concrete. This study insures that reusing of recycled rubber waste in sand concrete gives a positive approach to reduce the cost of materials and solve some environmental problems.
\end{abstract}

Key words: Rubber; recycling; sand concrete.

\section{Introduction}

The fraction of rubber waste in household wastes is large and increases with time. In each country the waste composition is different, since it is affected by socioeconomic characteristics, consumption patterns and waste management programs, but generally the level of rubber in waste composition is high. The large volume of materials required for construction is potentially a major area for the reuse of waste materials. Recycling in concrete has advantages since it is widely used and has a long service life, which means that the waste is being removed from the waste stream for a long period. Many authors have reported the properties of concrete with used tyre rubbers. Their results indicate that the size, proportion, and surface texture of rubber particles affect the strength of used tyre rubber contained in concrete (Khatib et al., 1999; Fedroff et al., 1996; Eldin and Senouci, 1993; Ali et al., 2000; Rostami et al., 2000; Topcu, 1995; Fattuhi and Clark, 1996; Naik and Singh, 1991; Siddique and Naik, 2004; Lee et al., 1998; Goulias and Ali, 1998) . Eldin et al (1993) conducted experiments to examine the strength and toughness properties of rubberised concrete mixtures. They used two types of tyre rubber, with different tyre rubber content. Their results indicated approximately $85 \%$ reduction in compressive strength, whereas the splitting tensile strength reduced by about $50 \%$ when the coarse aggregate was fully replaced by chipped tyre rubber. A smaller reduction in compressive strength $(65 \%)$ was observed when sand was fully replaced by fine crumb rubber. Concrete containing rubber did not exhibit brittle failure under compression or splitting tension and had the ability to absorb a large amount of energy under compressive and tensile loads. A more indepth analysis of their results indicates that an optimised mixture proportion is needed to optimise the tyre rubber content in the mixture. In recent years, used tyre chipped rubber 
containing Portland cement concrete for uses in sound/crash barriers, retaining structures, and pavement structures has been extensively studied (Khatib et al., 1999; Eldin and Senouci, 1993; Ali et al., 2000) . Test results showed that the introduction of used tyre chipped rubber considerably increases toughness, impact resistance, and plastic deformation but in almost all cases a considerable decrease in strength was observed. Khatib et al (1999) studied the influence of adding two kinds of rubber, crumb (very fine to be replaced for sand) and chipped (at the size of $10-50 \mathrm{~mm}$ to be replaced for gravel). They made three groups of concrete mixtures. In group A, crumb rubber to replace fines, in group B, chipped rubber to replace coarse aggregate, and in group $C$ both types of rubber were used in equal volumes. In all, the three groups had eight different rubber contents in the range of 5-100\% were used. They found that the compressive strength of concrete would decrease with increasing rubber content. For example, replacing $100 \%$ gravels by chipped rubber would decrease the compressive strength of concrete up to $90 \%$. Meanwhile, they showed that the rubberised concrete made with chipped rubber has less strength than concrete made with crumb rubber.

This work focuses on the possibility of recycling rubber waste of shoes without any prior treatment as a partial replacement of natural aggregate in sand concrete, in order to minimize the cost of the final material. The influence of the proportion of rubber waste used on properties of the new material has been studied and analyzed.

\section{Experimental program}

\subsection{Materials}

The sand used was a dune sand available in south of Algeria, near the city of Tamanrasset. The particle size distributions of the used sand are shown in Figure 1 and the physical characteristics are presented in Table 1.

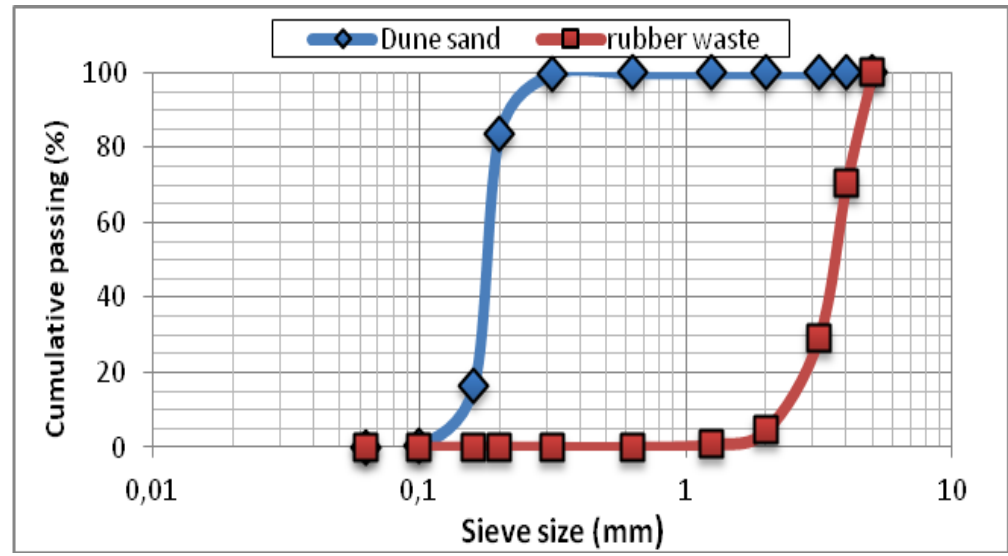

Fig 1. Particle size distribution of sand and rubber waste used.

Table 1. Physical properties of used sand.

\begin{tabular}{|l|c|c|}
\hline Properties & Sand & Standard \\
\hline \hline Bulk density $\left(\mathrm{kg} / \mathrm{m}^{3}\right)$ & 1400 & NP EN 1097-3 \\
\hline Specific density $\left(\mathrm{kg} / \mathrm{m}^{3}\right)$ & 2560 & NP EN 1097-6 \\
\hline Water absorption $(\%)$ & 2.66 & NP EN 1097-6 \\
\hline Sand equivalent (\%) & 80.50 & NP EN 933-8 \\
\hline Fineness modulus & 0.84 & NP EN 933-1 \\
\hline Compactness (\%) & 0.55 & NF P 18-555 \\
\hline Porosity (\%) & 0.45 & NF P 18-555 \\
\hline Thermal conductivity $(\mathrm{W} / \mathrm{m} \mathrm{K})$ & $1.3-1.4$ & NF EN ISO 8894-1 \\
\hline
\end{tabular}


An industrial Portland cement CPJ-CEM II/A of class 42.5 is used. The physical characteristics are the following: specific density $3100 \mathrm{~kg} / \mathrm{m}^{3}$ and specific surface area $308 \mathrm{~m}^{2} / \mathrm{kg}$, was used for all sand concrete mixtures.

The use of fillers in sand concrete composition is essential (AFNOR 1994). Their use is intended to complete the grading curve of sand in its finest part in order to obtain more compact concrete and reduce the cement content and therefore the cost of concrete. In this work the fillers used are the limestone powder. Their specific density is $2660 \mathrm{~kg} / \mathrm{m}^{3}$, and specific surface area 242 $\mathrm{m}^{2} / \mathrm{kg}$.

The rubber waste used in this work were obtained by the recycling the waste of shoes (Figure 2) discharged into the nature after were collected, are washed, compressed, crushed and extruded in the form of grains, and added in the mass of sand concrete with percentage $110 \%, 20 \%, 30 \%$ and 40\%).The sieve analysis results are given in Figure 1, and the Table 2 lists the set of physical and thermal properties.
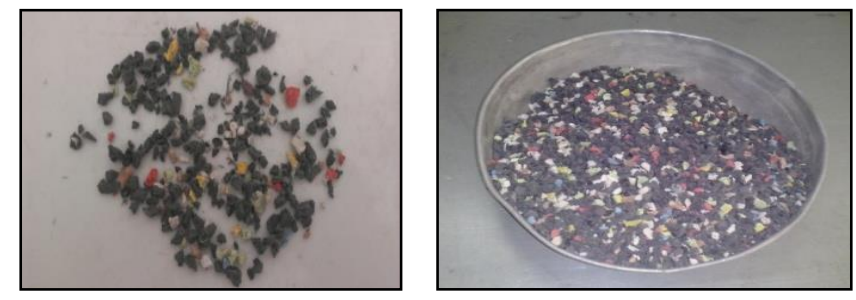

Fig 2. Particle size distribution of sand and rubber waste used.

Table 2. Physical and thermal properties of used rubber waste.

\begin{tabular}{|l|c|c|}
\hline Properties & Rubber waste & Standard \\
\hline \hline Bulk density $\left(\mathrm{kg} / \mathrm{m}^{3}\right)$ & 1500 & NP EN 1097-3 \\
\hline Specific density $\left(\mathrm{kg} / \mathrm{m}^{3}\right)$ & 800 & NP EN 1097-6 \\
\hline Water absorption $(\%)$ & 1.28 & NP EN 1097-6 \\
\hline Fineness modulus & 3.2 & NP EN 933-1 \\
\hline Compactness $(\%)$ & 53 & NF P 18-555 \\
\hline Porosity (\%) & 47 & NF P 18-555 \\
\hline Thermal conductivity $(\mathrm{W} / \mathrm{m} \mathrm{K})$ & 0.15 & NF EN ISO 8894-1 \\
\hline
\end{tabular}

A polycarboxylate plasticizer (Medafluid 104) produced by GRANITEX group (Algeria) with solid contents of $35 \%$ was used for all mixes. The mixing water used for the different mixes is the drinking water, free of impurities with a PH equal to 7.

\subsection{Mix design}

In this work, the optimal compositions of the sand concrete studied, without rubber waste, is based on the experimental method of project of Sablocrete (SABLOCRETE 1994). This gave for cement proportioning of $350 \mathrm{~kg} / \mathrm{m}^{3}, 1200 \mathrm{~kg} / \mathrm{m}^{3}$ of sand, $250 \mathrm{~kg} / \mathrm{m}^{3}$ of fillers, and a water/cement ratio of 0.85 , a percentage of plasticiser of $1 \%$ of weight of cement. The rubber waste is added in sand concrete at dosages $(0 \%, 10 \%, 20 \%, 30 \%$ and $40 \%)$. Literary codes identify each mixture in a precise way:

- CSC: Control sand concrete (without rubber).

- SCRW: Sand concrete with rubber waste.

All specimens were produced in laboratory environment with $20^{\circ} \mathrm{C}$ and $50 \% \mathrm{RH}$. After $24 \mathrm{~h}$, they were removed from the molds and placed in water at $20^{\circ} \mathrm{C}$ and $100 \%$ relative humidity until the day of testing. This procedure was respected for all compositions and all tests. 


\subsection{Test procedure}

The workability of concrete was measured in terms of slump according to NF P 18-451. The flexural strength was measured on $40 \times 40 \times 160 \mathrm{~mm}$ specimens at the ages of 28 days by a threepoint bending test, using a testing machine according to EN 196-1.The half-samples resulting from this test were then submitted to compression test. The measurements of thermal conductivity led to the determination of the following parameters: thermal conductivity $(\lambda)$, on three $40 \times 80 \times 160 \mathrm{~mm}$ samples using a CT-Meter machine.

\section{Results and discussion}

\subsection{Workability}

The slump of sand concrete as a function the content of rubber waste is sowed in Figure 3. The use of rubber waste as addition in sand concrete contributes to increase the slump of sand concrete, probably due to the presence of more free water in the mixes containing rubber than in the concrete mix containing natural aggregate since, unlike natural aggregate, rubber aggregate has a lower absorption coefficient than dune sand, which is in concordance with the results of Guendouz et al (2016). Khatib et al (1999) investigated the workability of rubcrete and reported that there is a decrease in slump with increase in rubber content as a percentage of total aggregate volume. They further noted that at rubber contents of $40 \%$, slump was almost zero and concrete was not workable manually. It was also observed that mixtures made with fine crumb rubber were more workable than those with coarse tire chips or a combination of tire chips and crumb rubber. Siddique and Naik (2004) have reported that mortars incorporating rubber shreds achieved workability comparable to or better than a control mortar without rubber particles It was also observed that mixtures made with fine crumb rubber were more workable than those with coarse tire chips or a combination of tire chips and crumb rubber.

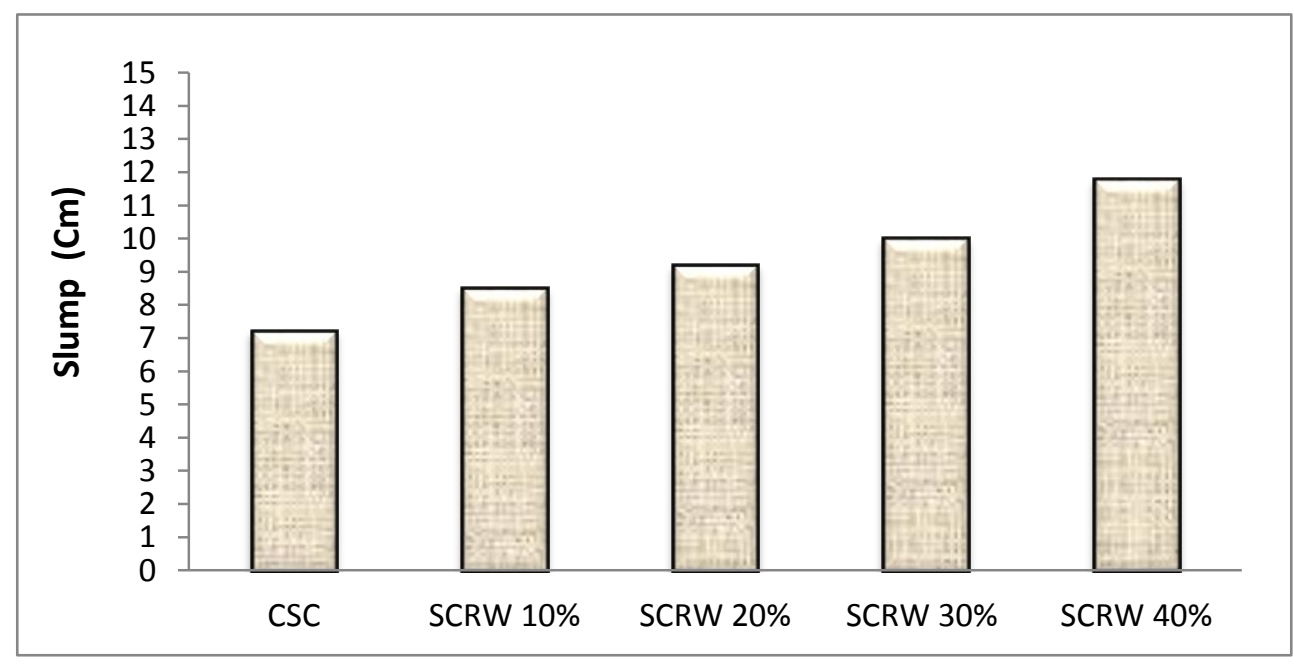

Fig.3. Slump of sand concrete as function of rubber waste content.

\subsection{Bulk density}

According to the results presented in Figure 4, the use of rubber waste as addition in sand concrete contributes to reduce the bulk density, probably due to the lower density of the rubber compared with the dune sand, which is in concordance with the results of Guendouz et al (2015). Khatib et al (1999) concluded that because of low specific gravity of rubber particles, unit weight of mixtures containing rubber decreases with the increase in the percentage of rubber content. Moreover, increase in rubber content increases the air content, which in turn 
reduces the unit weight of the mixtures. The decrease in unit weight of rubcrete is found to be negligible when rubber content is lower than $10-20 \%$ of the total aggregate volume.

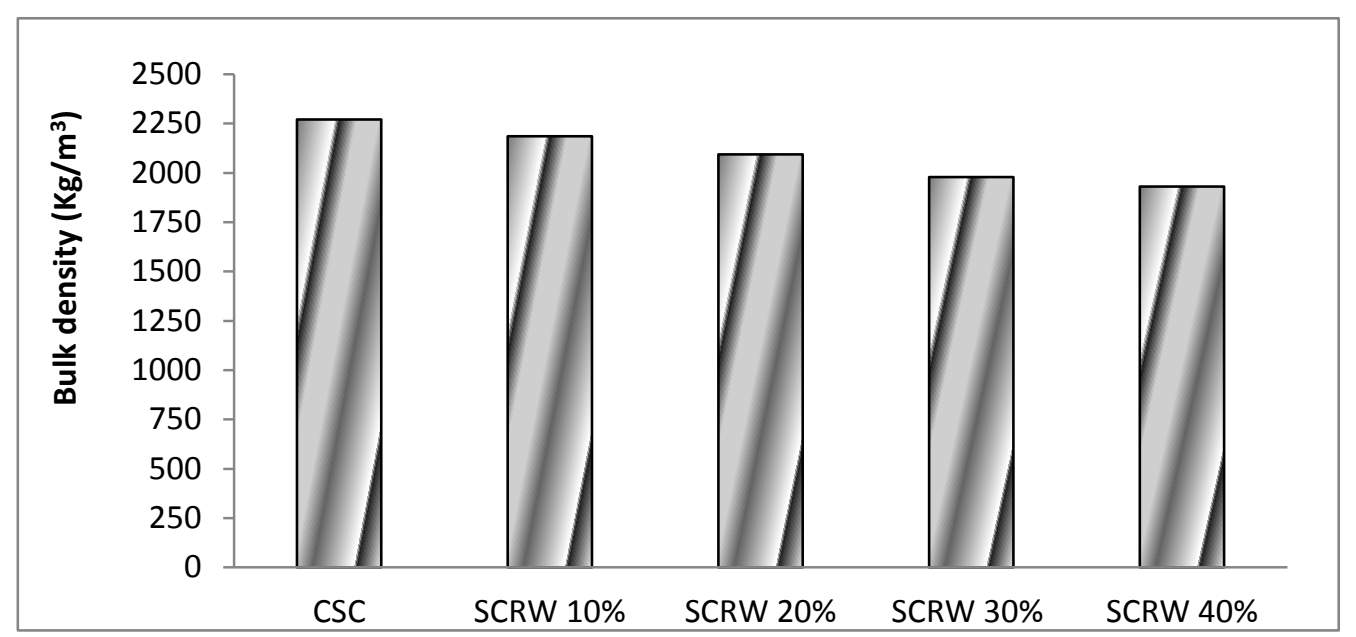

Fig.4. Bulk density of sand concrete as function of rubber waste content.

\subsection{Mechanicals strength}

The results of compressive and flexural strength of different sand concretes at 28 days of age are presented in Figure 5 and 6 respectably. The results displayed in Figure 5 and 6 show that compressive strengths of sand concrete decrease $15.7 \%$ respectively for addition of $40 \%$ natural dune sand by rubber waste. Event thing in the case of the flexural strengths, which indicates that the addition of $40 \%$ of the rubber waste in a sand concrete represents decrease the performances of new materials. This trend may be related to a poor adhesion between the surface of the rubber aggregate and binder paste which is likely to have contributed to such a strong decay of mechanical properties. Eldin and Senouci (1993) compared the use of rubber as coarse aggregates and the use of rubber chips as sand. The reductions of up to $85 \%$ of the compressive strength were observed when the coarse aggregate was replaced by rubber. A smaller reduction in compressive strength $(65 \%)$ was observed when sand was replaced by crumb rubber. It was further observed that rubber-containing concrete did not exhibit brittle failure under compression. The strength reduction can be attributed both to a reduction of the quantity of the solid load-carrying material and to stress concentrations (tensile and compressive) in the paste at the boundaries of the rubber aggregate.

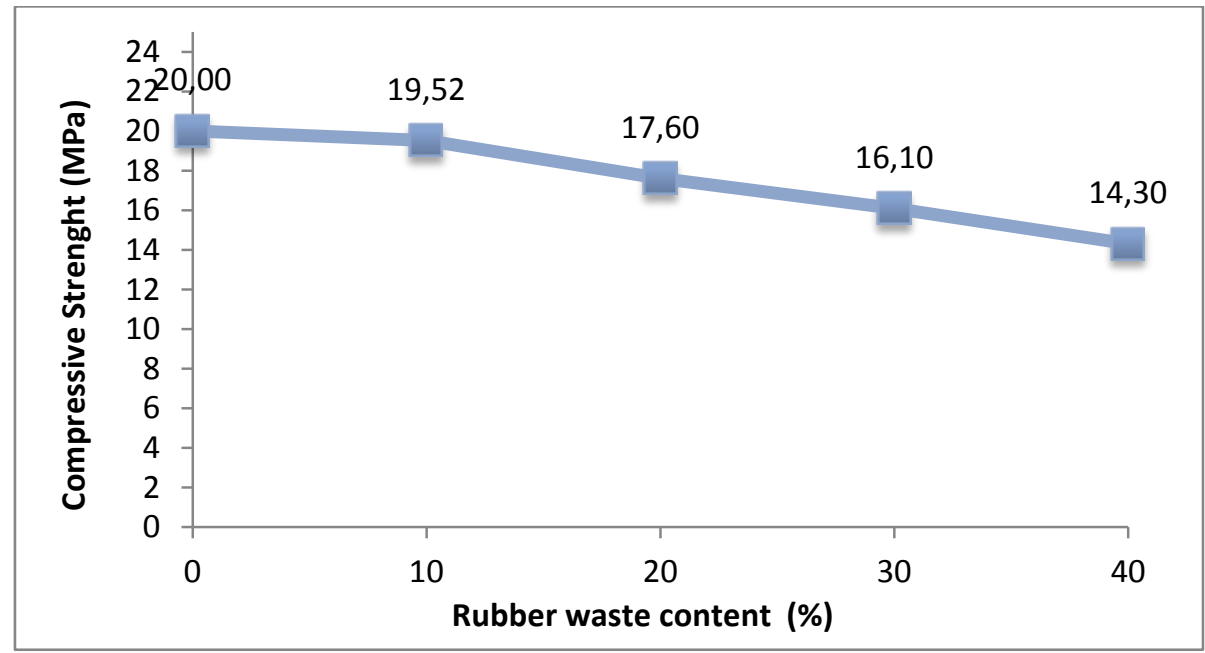

Fig.5. Compressive strength of sand concrete as function of rubber waste content. 


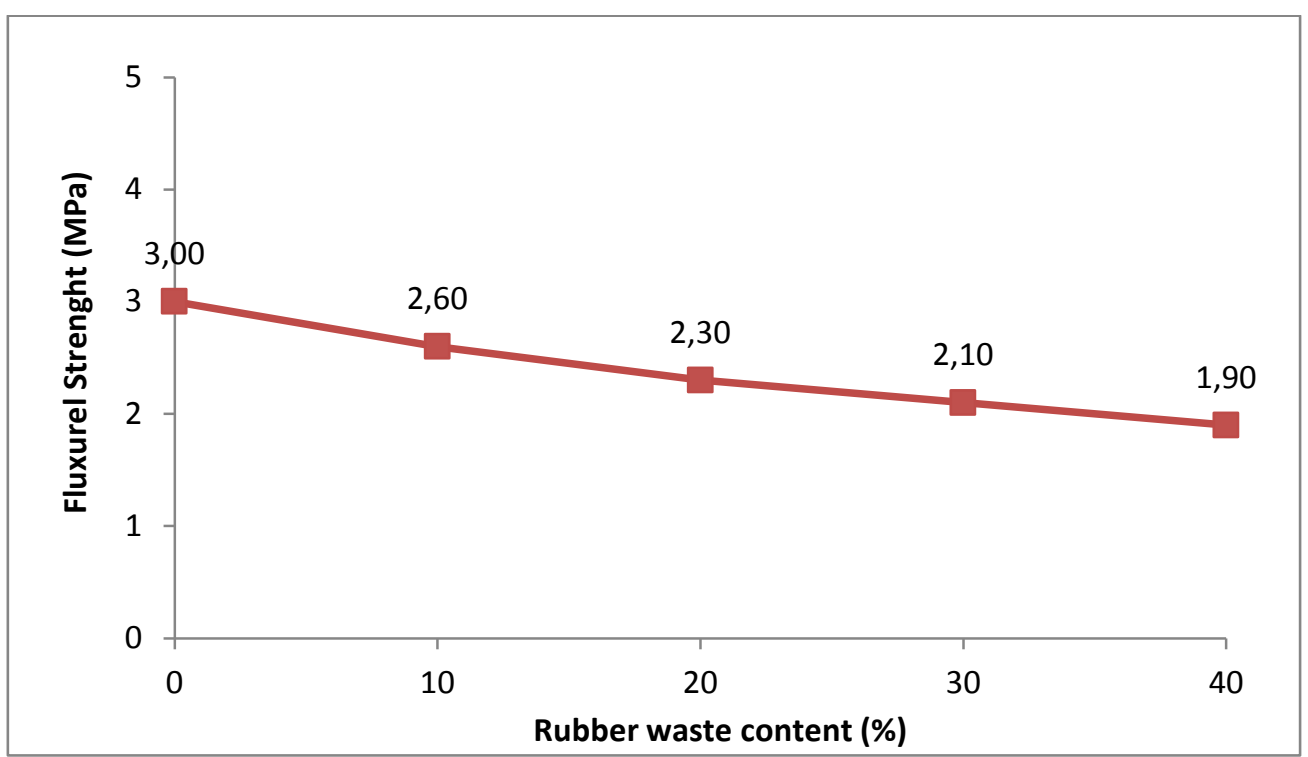

Fig.6. Flexural strength of sand concrete as function of rubber waste content.

\subsection{Thermal Conductivity}

Figure 7 give the thermal conductivity values of the specimens measured at 28 days. The thermal conductivity value of control sand concrete was $1.58 \mathrm{~W} / \mathrm{m} \mathrm{K}$. This value decreased to $1.02 \mathrm{~W} / \mathrm{m} \mathrm{K}$ for dune SC when the replacement of rubber wastes into mixture with normal aggregate at a ratio of $40 \%$. Rubber waste aggregate addition into SC composites caused the reduction in the values of $\mathrm{TC}$ of the specimens. It is thought that, this situation caused by the lower thermal conductivity value of the rubber $(0.15 \mathrm{~W} / \mathrm{m} \mathrm{K})$ than natural aggregate $(2 \mathrm{~W} / \mathrm{m} \mathrm{K})$ Iucolano et al (2013). So the decreasing thermal conductivity came also from the increase in porosity induced by the rubber waste. In fact the pores contain air which has a thermal conductivity value $(0.024 \mathrm{~W} / \mathrm{mK})$ much lower than all the other components of the SC. Similar results were observed by several authors in composite systems, for example Hannawi et al. (2010) in a study on PF and PET in mortar composites, and it's showed a decreased in value of thermal conductivity of mortar containing PET about 50\% lower than a traditional mortar. Akçaözog lu et al.(2013) find that the PET aggregate replacement with natural aggregate in mixture caused a reduction in the values of thermal conductivity value of the specimens.

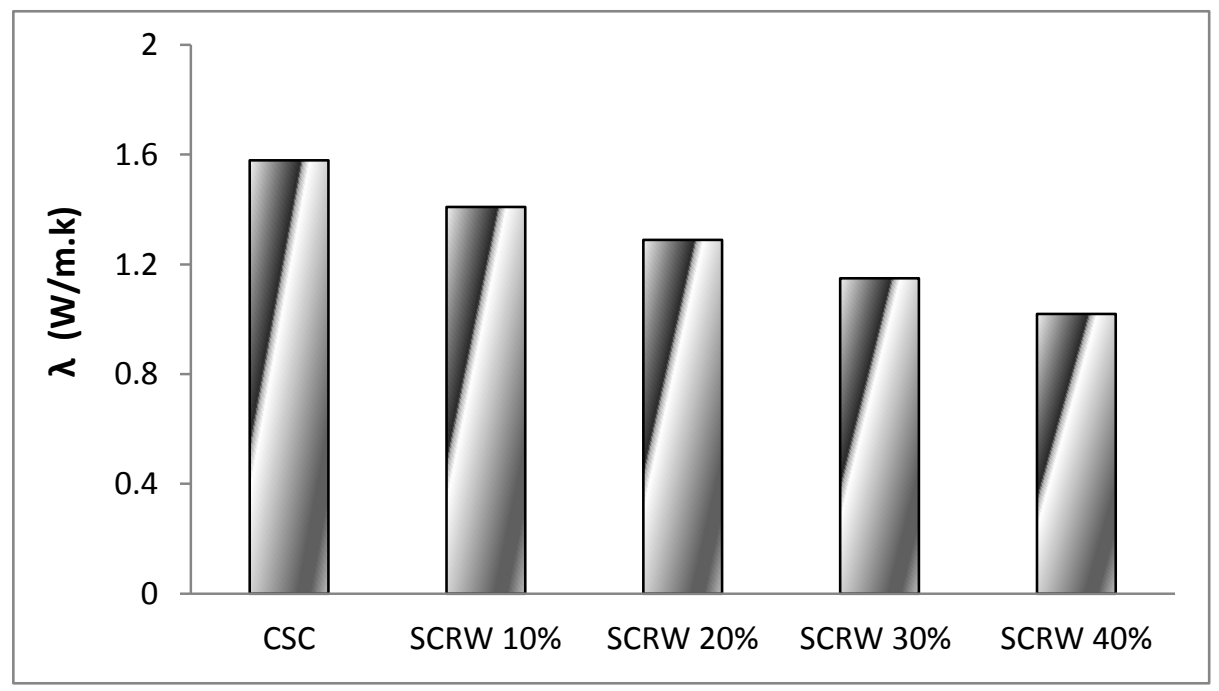

Fig.7. Thermal conductivity of sand concrete as function of rubber waste content. 


\section{Conclusions}

This paper has presented the recycling and the use of rubber wastes as aggregate in sand concrete produced either from dune sand (DS). The results which could be summarized and concluded as:

1-These types of rubber wastes types can be used in sand concrete.

2-The workability of all sand concrete increases and the density decreases with the increase of rubber waste shoes content.

3-The compressive and flexural strength values of all waste rubber SC mixtures tend to decrease above the values for the reference SC with increasing the waste rubber ratio. But this result was acceptable for lightweight concrete.

4 - The addition of $40 \%$ of rubber waste in sand concrete caused a reduction (35\%) in the values of thermal conductivity. This result is primarily due to lower thermal conductivity of the rubber waste, but also to the capacity of the aggregate rubber to facilitate the formation of micro voids which improves the thermal insulation performances of the sand concrete.

The use of rubber waste of shoes as aggregates in sand concrete can most of the problems associated with their disposal as well as save natural resources related to aggregates mining.

\section{References}

AFNOR. Concrete - Sand concrete. (1994).Projet P 18-500 [in French].

Akçaözoğlu, S., Akçaözoğlu, K., \& Atiş, C. D. (2013). Thermal conductivity, compressive strength and ultrasonic wave velocity of cementitious composite containing waste PET lightweight aggregate (WPLA). Composites Part B: Engineering, 45(1), 721-726.

Ali NA., Amos AD., Roberts M.(2000). Use of ground rubber tires in Portland cement concrete. In: Proceedings of the international conference on concrete. Scotland (UK): University of Dundee.

Eldin NN., Senouci AB.(1993). Rubber_tyre particles as concrete aggregates. ASCE J Mater Civil Eng. 1993.478-96.

Fattuhi, N. I., \& Clark, L. A. (1996). Cement-based materials containing shredded scrap truck tyre rubber. Construction and building materials, 10(4), 229-236.

Fedroff, D., Ahmad, S., \& Savas, B. (1996). Mechanical properties of concrete with ground waste tire rubber. Transportation Research Record: Journal of the Transportation Research Board, (1532), 6672.

Guendouz, M., Debieb, F., Boukendakdji, O., Kadri, E. H., Bentchikou, M., \& Soualhi, H (2016). Use of plastic waste in sand concrete.J. Mater. Environ. Sci. 7 (2) 382-389.

Guendouz, M., \& Debieb, F. (2015). Formulation et caractérisation d'un béton de sable à base de déchets plastiques. In 33èmes Rencontres Universitaires de Génie Civil.". Bayonne, France, p 1-8.

Goulias, D. G., \& Ali, A. H. (1998). Evaluation of rubber-filled concrete and correlation between destructive and nondestructive testing results. cement, concrete and aggregates, 20(1), 140-144.

Hannawi K., Kamali-Bernard S., Prince W.(2010). Physical and mechanical properties of mortars containing PET and PC waste aggregates. Waste Management .30.2312-20.

Iucolano F., Liguori B., Caputo D., Colangelo F., Cioffi R.(2013). Recycled plastic aggregate in mortars composition: Effect on physical and mechanical properties. Materials and Design.52. 916-922.

Khatib ZK. Bayomy FM.(1999). Rubberized portland cement concrete. ASCE J Mater Civil Eng.11(3) .20613

Lee HS., Lee H., Moon JS.(1998). Development of tire-added latex concrete. ACI Mater J.95(4):356-64. 
Naik TR., Singh SS. Utilization of discarded tyres as construction materials for transportation facilities. Report No. (1991).CBU-02,UWM Center for By-products Utilization. Milwaukee: University of Wisconsin-Milwaukee.

SABLOCRETE (1994). 'Béton de sable : Caractéristiques et pratique d'utilisation'. Presse de l'Ecole Nationale des Ponts et Chaussées.

Rostami, H., Lepore, J., Silverstraim, T., \& Zundi, I. (2000). Use of recycled rubber tires in concrete. In Proceedings of the international conference on concrete (Vol. 1993, pp. 391-399). London, United Kingdom: Thomas Telford Services Ltd.

Siddique, R., \& Naik, T. R. (2004). Properties of concrete containing scrap-tire rubber-an overview. Waste management, 24(6), 563-569.

Topcu, I. B. (1995). The properties of rubberized concretes. Cement and concrete research, 25(2), 304-310. 